\title{
The Research of Tesco's Current Investment Portfolio and Some Recommendations
}

\author{
Jiaying Ren
}

\author{
Business Administration (Accounting), Asia Australia Business School, Liaoning University, Shenyang, Liaoning \\ province, 110010, China. \\ Corresponding author's email: gaoming@cas-harbour.org
}

\begin{abstract}
The aim of this research is to make some recommendation to the investment portfolio identifying the return and risk of Tesco. The methods used are financial statement analysis, comparison of return models, risk assessment criteria and ways to plan portfolio adjustments. This paper studies Tesco's current portfolio through the analysis of several common enterprise investment tools, such as return analysis of stocks and bonds, and hedging analysis of foreign exchange. The data comes from Tesco's financial statements for 2021, with changes backdated to this year's and the previous year's figures, as well as proportional gains and losses. The research is insisted of the current conclusion of the portfolio situation and some suggestions for the future adjustment.
\end{abstract}

Keywords: Asset, Investment, portfolio, return

\section{INTRODUCTION}

This paper aims to analyze the current portfolio, in order to put forward the proposal that makes Tesco's investment portfolio more profitable and efficient. Because of the volatility of the capital market, the corresponding investment portfolio of the company needs to make certain adjustments to ensure the maximization of its interests. By evaluating the return on investment of Tesco Company and study the fixed part and the liquid part of its market funds. Furthermore, it investigates the risk of its portfolio through liquidity and risk-return model.

\section{CURRENT INVESTMENT PORTFOLIO RESEARCH}

\subsection{Investing Management}

\subsubsection{Bonds and Stocks}

Tesco's mainly investment portfolio is consisted of bonds and shares. First of all, calculate the total amount of Tesco's capital available for investment. This includes all tangible assets, i.e. furniture, appliances and goods, rent that are not due, book value of the company, and valuable items such as stocks and bonds. The net assets are obtained as follows: $£ 12,325 \mathrm{~m}$, in addition, there are operating profits of intangible assets of $£ 4,250 \mathrm{~m}$. The total amount available for investment is therefore $£$ $16,575 \mathrm{~m}$. Among them, the total amount invested in stocks is $7268 \mathrm{~m}$, and the carrying value now held is ( $£$ $2,557 \mathrm{~m})$. This represents an overall downward trend in the company's existing stock holdings. A comparison between 2021 and 2020 also shows that stocks were worth more last year than they were this year. Tesco has already sold some of its most vulnerable shares, such as $2.5 \% \mathrm{MTN}$, and has yet to mature, according to a survey of trends in a large proportion of the stocks. The portion that matures by 2024 earned more than $15 \%$ of its face value last year, but this year it has fallen by $£ 58 \mathrm{~m}$. The total stock involved is multiplied twice as much as 2020 . This part's contribution to the whole portfolio is less than that of bonds. As a result, the bond investment needed to be adjusted because of some of the projects' rate of return fluctuation. (Figure on the next page) 


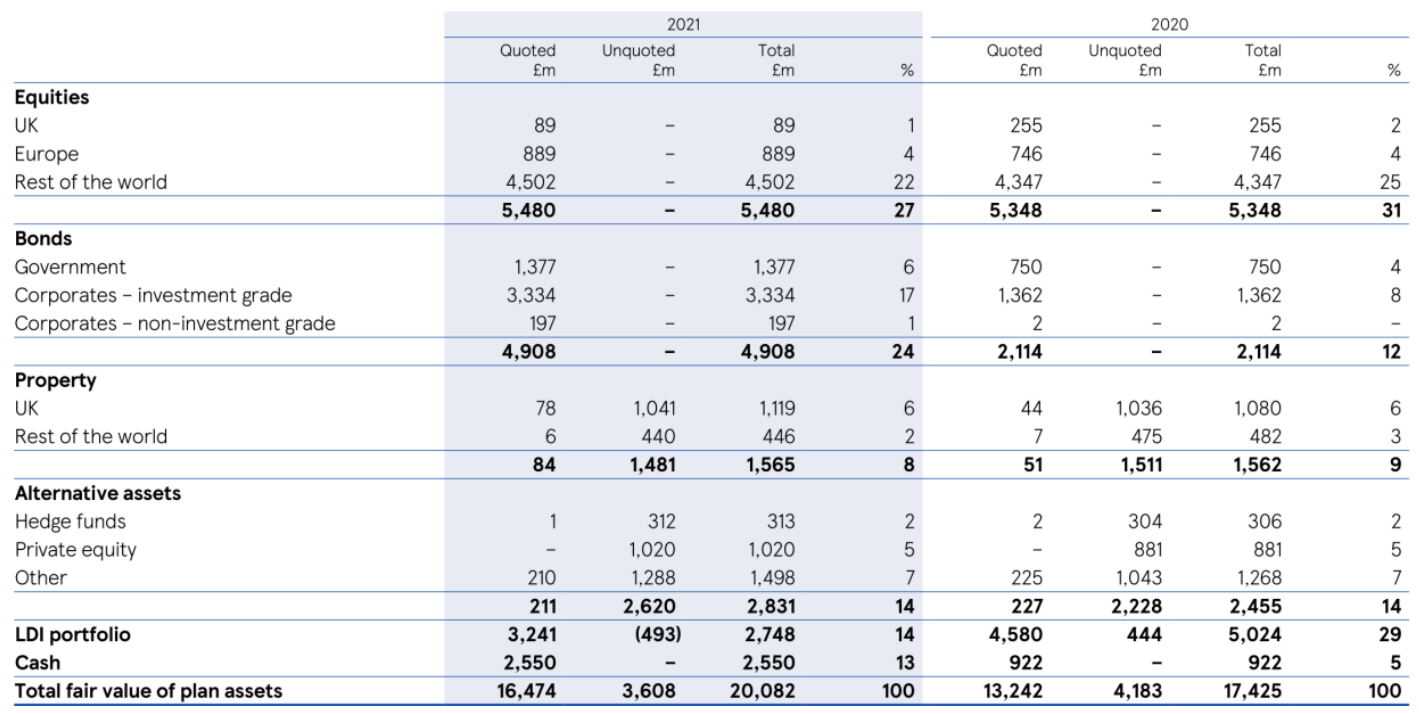

Figure 1. Bonds investment.

\begin{tabular}{|c|c|c|c|c|}
\hline & Par value & Maturity & $\begin{aligned} 2021 \\
\varepsilon m\end{aligned}$ & $\begin{array}{c}2020^{\infty} \\
\mathrm{Em}\end{array}$ \\
\hline Bank loans and overdrafts ${ }^{(a)}$ & - & - & 559 & 1,142 \\
\hline $2.125 \%$ MTN & $€ 296 \mathrm{~m}$ & Nov 2020 & - & 255 \\
\hline $1 \mathrm{~m}$ USD LIBOR + $0.70 \%$ Tesco Bank Bond & $\$ 350 m$ & Nov 2020 & - & 273 \\
\hline $5 \%$ Tesco Bank Retail Bond & $£ 200 m$ & Nov 2020 & - & 202 \\
\hline $6.125 \%$ MTN & $£ 417 \mathrm{~m}$ & Feb 2022 & 417 & 416 \\
\hline LIBOR + 0.53\% Tesco Bank Bond & $£ 300 \mathrm{~m}$ & Oct 2022 & - & 299 \\
\hline $5 \%$ MTN $^{(b)}$ & $£ 71 \mathrm{~m}$ & Mar 2023 & 79 & 103 \\
\hline $1.375 \%$ MTN & $€ 750 \mathrm{~m}$ & Oct 2023 & 662 & 660 \\
\hline $2.5 \%$ MTN $^{(b)}$ & $€ 473 m$ & Jul 2024 & 415 & 653 \\
\hline $2.5 \%$ MTN & $£ 400 \mathrm{~m}$ & May 2025 & 417 & 418 \\
\hline 3.5\% Tesco Bank Senior MREL Notes ${ }^{(h)}$ & $£ 250 \mathrm{~m}$ & Jul 2025 & 251 & 250 \\
\hline 3.322\% LPI MTN" & $£ 354 m$ & Nov 2025 & 364 & 358 \\
\hline $0.875 \%$ MTN & $€ 750 \mathrm{~m}$ & May 2026 & 649 & 640 \\
\hline $5.5457 \%$ Secured Bond ${ }^{(c) / d)}$ & $£ 289 m$ & Feb 2029 & 275 & 303 \\
\hline $6.067 \%$ Secured Bond ${ }^{(c)}$ & $£ 200 \mathrm{~m}$ & Feb 2029 & 193 & 192 \\
\hline LIBOR + $1.2 \%$ Secured Bond ${ }^{(c)}$ & $£ 50 \mathrm{~m}$ & Feb 2029 & 48 & 36 \\
\hline $0.375 \%$ MTN & $€ 750 \mathrm{~m}$ & Jul 2029 & 625 & - \\
\hline $6 \% \mathrm{MTN}^{(\mathrm{b})}$ & $£ 38 m$ & Dec 2029 & 45 & 58 \\
\hline $2.75 \%$ MTN & $£ 450 \mathrm{~m}$ & Apr 2030 & 441 & - \\
\hline LIBOR + 1.17\% Secured Bond $d^{(f(i)}$ & $£ 187 \mathrm{~m}$ & Jan 2032 & 184 & - \\
\hline LIBOR + 1.17\% Secured Bond ${ }^{(t)}$ & $£ 108 \mathrm{~m}$ & Jan 2032 & 100 & - \\
\hline $5.5 \% \mathrm{MTN}^{(b)}$ & $£ 67 \mathrm{~m}$ & Jan 2033 & 80 & 133 \\
\hline 1.982\% RPI MTN" & $£ 294 m$ & Mar 2036 & 302 & 297 \\
\hline $6.15 \%$ USD Bond $d^{(b)}$ & $\$ 355 m$ & Nov 2037 & 333 & 555 \\
\hline $6.0517 \%$ Secured Bond ${ }^{(\mathrm{e})(\mathrm{g})}$ & $£ 458 \mathrm{~m}$ & Oct 2039 & 592 & 616 \\
\hline $4.875 \% \mathrm{MTN}^{(b)}$ & $£ 14 m$ & Mar 2042 & 14 & 20 \\
\hline $5.125 \%$ MTN $^{(b)}$ & $€ 235 \mathrm{~m}$ & Apr 2047 & 209 & 316 \\
\hline \multirow[t]{2}{*}{$5.2 \% \mathrm{MTN}^{(b)}$} & $£ 14 m$ & Mar 2057 & 14 & 29 \\
\hline & & & 7,268 & 8,224 \\
\hline \multicolumn{5}{|l|}{ Of which: } \\
\hline Current & & & 1,080 & 2,219 \\
\hline \multirow[t]{2}{*}{ Non-current } & & & 6,188 & 6,005 \\
\hline & & & 7,268 & 8,224 \\
\hline
\end{tabular}

Figure 2. Shares investment.

\subsubsection{Securities}

Low credit risk investments include, in addition to cash and cash equivalents, short-term investments, other financial assets of fair value consolidated earnings (FVOCI), depreciation expense standard financial assets, and the investment grade (BBB or above) or short-term nature of the investment securities owned by the customer are applied [4]. In the 2020 fiscal year, short-term investments such as securities within money market increased from $£ 390 \mathrm{~m}$ to $£ 1096 \mathrm{~m}$, could be regarded as the cash invested in money markets with long-term credit ratings has increased, but returns in 2021 are smaller than in 2020. Therefore, the input is also appropriately lowered. As a large multinational enterprise, such slight adjustment has an immeasurable effect on the development of the whole enterprise. If this part of the loss cannot be recovered, the whole company could face several million pounds of cash loss.

\subsubsection{Foreign exchanges}

In addition, foreign exchanges are involved because Tesco is a transnational enterprise. As at 27 February 2021, the forward FX contracts, designated by the Group 
as cash flow hedges, had a balance of $£ 2.5$ billion (approximately $£ 400$ million more than 2020). These forward contracts mainly involve purchases of euros, with a book value of 1 billion euros, and dollars, with a book value of 1.3 billion dollars. These purchases are made in annual increments of 25 per cent. Expiration dates vary and run until August 2022. The above currencies traded in a range of exchange rate: 1.08 to 1.156 EUR/GBP and 1.222 to 1.416 USD/GBP [1]. Tesco hedged its exposure to some of its net investments in its overseas operations by borrowing in Euros, thus offsetting the change in value due to changes in foreign exchange rates. The hedging risk of net investment hedging, also the depreciation of the euro against the pound will reduce the book value of the group's net euro investment. To evaluate the hedging effectiveness, Tesco has established the hedging ratio $1: 1$, to determine the economic relation of the hedging instrument, and the hedged item is the carrying amount of the debt caused by the spot exchange rate which changes with the change of investment changes due to fluctuation at the spot exchange rate of the operation of foreign exchange, the potential risk of this ratio as a hedging tool is the same as the composition of the hedged risk.

\subsubsection{Derivatives: swaps}

Derivatives to hedge market exposures, including: economic hedging, formally designated hedging using hedge accounting instruments. The main source of hedging ineffectiveness is the counterparty and the Group's credit risk that affects the fair value of proprietary derivatives. During the year as the annual report showed, the net investment hedge invalid value was $£ 0$ (the same as 2020), the Group disposed of its Asian business and therefore carried the translated income back to the income statement with $£ 57 \mathrm{~m}$, which is a new added investment in related to the net investment hedge. During the current financial year, currency movements reduced the net value of the Group's overseas assets after hedging by $£ 68 \mathrm{~m}$ (the same as 2020). The Group also ensures that each subsidiary appropriately hedges its non-functional currency assets. The Group's policy does not permit the use of derivatives for trading purposes [5]. However, some derivatives are not eligible for hedging accounting, or gains and losses that are not explicitly designated as hedging instruments in the hedging statement are offset by the hedged items. These instruments include index-linked swaps, interest rate swaps, cross-currency swaps in foreign currencies.

Among them, the total cash outflow is minus $£ 2410 \mathrm{~m}$ $(1206+905+299 \mathrm{~m})$.

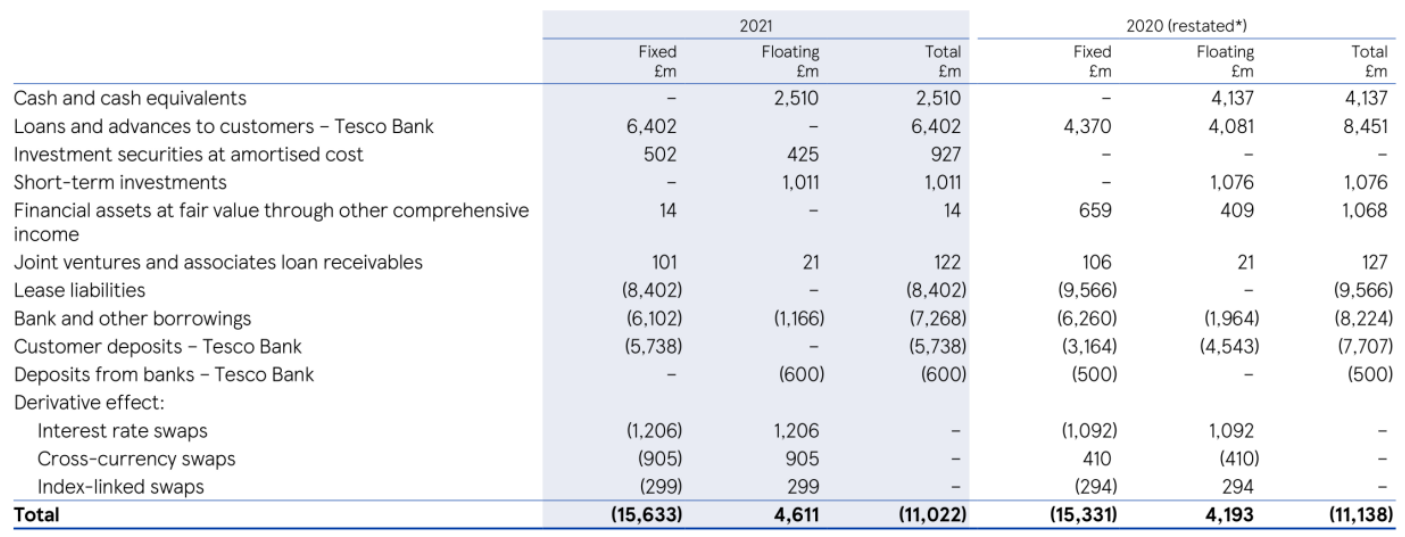

Figure 3. Swaps.

\subsection{Return Analyses}

There are two main ways to measure the rate of return on investment, namely the average rate of return and geometric rate of return commonly used by people. Average return: The mathematical average of a series of returns generated over a specified period of time. The average return is calculated the same way as a simple average for any set of numbers. These numbers add up to a sum, which is then divided by the number of numbers in the set. Average returns can help measure the past performance of a security or portfolio. The drawback of this calculation cannot be ignored: it is not the same as the annualized return, because it ignores compound interest. In contrast, the geometric average is always lower than the average return [3].

For a company like Tesco, the geometric rate of return is more applicable to study its portfolio performance. Because the longer the investment, the more important it is to compound. When investing in stocks and bonds, the cumulative return of each period is calculated by multiplication, so the result is more accurate and closer to the actual investment value is the geometric rate of return. This yield is recommended for the ratio of Tesco shares to bonds. Use the approximation to calculate geometric return is around minus $0.85 \%$. that is the real return of the bonds-shares portfolio. From the security exchange of Tesco's 
investment of its eight shares, the downward trend of $6.15 \%$ SNR NTS $15 / 11 / 37$ is the most significant. In addition, bond investment situation was mentioned above, which also needed to be adjusted.

\section{RISK ANALYSES}

\subsection{Systematic Risk}

The Group will continue to monitor the market and the output of various industry groups, and while managing the transition to the new benchmark rate, it will seek to implement retreat. It is appropriated on different instruments and international interbank rates. For the Group's derivatives, in 2019, the International Swaps and Derivatives Association (ISDA) introduced a stand-by clause, and the Group has initiated discussions with its banks and other counter parties with the aim of implementing these rules and other related agreements in ISDA [6]. The group's transition to alternative benchmarks is being managed by a cross-functional team, led by the Treasury team from the retail business and Tesco Bank, with the aim of completing the transition in the financial year ending 26 February 2022. However, the Group does not believe that these risks will materialize as significant progress has been made in transforming transactions with banks and other counter parties. In addition, inflation risk that contained index-linked debt, lease liability indexed to the inflation index and so on.

\subsection{Idiosyncratic risk}

Due to the nature of retail and Tesco banking operations, due to the large number of customers, the risk concentration is low and spread over a wide geographical area. Maximum exposure to credit risk at the end of the reporting period, which reflects the book value of various financial assets, was $£ 26 \mathrm{bn}$ for the group (down 2.9bn from 2020). Net counter party exposure under derivatives contracts was £1.2bn [1]. The Group's maximum credit exposure is analyzed by category of financial instruments, including derivatives and central bank cash balances that are not subject to ECL. In addition, Tesco is exposed to commodity price risk, which involved its own used diesel. Its investment portfolio illustrated high-degree liquidity because the assets and return above are all involve acceptable ranges [2].

\section{RECOMMENDATIONS}

First of all, Tesco's overall portfolio was positive, except for some riskier long-term bonds. In the general investment statement, government bonds are regarded as an investment with stable returns, and Tesco can increase its investment in this part to make up for the possible losses caused by some risky investments. In addition, the plan asset of bonds raised from $£ 2114 \mathrm{~m}$ to $£ 4908 \mathrm{~m}$, and the percentage of bonds multiplied twice as much as last year. The investment of corporate bonds increased nearly $150 \%$. As a result, the bonds investment should increase about $£ 2000 \mathrm{~m}$ in order to meet the change of planned aspect changes. Moreover, government bonds should increase about $£ 1000 \mathrm{~m}$ so that risks would be balanced.

Secondly, according to shares, Tesco should maintain these stocks with considerable returns, although they are not mature enough to generate income for the company, but as part of the assets of the company there is no harm. In addition, the earnings of MTN mentioned above are declining year by year and there are still several years before the maturity period, so I suggest buying other stocks with less risk and shorter maturity period to make up for this loss. According to analysis, selling them now will result in a loss of about $5 \%$ of the total value of the stock purchased.

Next, Tesco's share of portfolio investment has risen sharply, to more than $60 \%$. But returns have fallen, suggesting that its analysis of the money market is skewed. In the face of inflation, it should indeed reduce the investment of money, i.e., increase the cash available within the firm, so it should sell around $\$ 500 \mathrm{~m}$ of securities to buy more valuable and less risky government bonds. In terms of foreign exchange purchase, it is recommended that Tesco increase its purchase of foreign exchange by $25 \%$ this year, as the impact of Brexit is basically negligible. Besides, in today's money market, it is more likely that the purchase of foreign exchange will appreciate later. It can also make up for other investment gaps. For derivatives, especially the swap contracts, most of them do not meet the conditions of Tesco hedging instruments to offset the gains and losses. Therefore, most of Tesco's performance this year shows negative growth. Therefore, the increased monetary savings can be used to balance the cash losses in forward contracts.

Lastly, based on its return analysis, my suggestion is also to adjust the above financial instruments. Therefore, the geometric rate of return is positive, which is more conducive to the operation and development of the company. Secondly, the management of risks should be increased, such as whether the company faces tail risks. Although Tesco rarely faces huge industry changes in various market environments, the company should also take precautions.

\section{CONCLUSION}

The analysis of Tesco's corporate investment portfolio shows that Tesco still suffers a small amount 
of losses in the choice of different investment instruments and bears certain risks. Most of Tesco's holdings have yet to reach earnings date and are worth less than they were in 2020. Secondly, Tesco has reduced the proportion of short-term investment in securities investment and greatly increased the long-term investment that may generate greater profits, which is tantamount to increasing part of the risk. In terms of foreign exchange, Tesco borrowed more euros to hedge the value changes caused by interest rate fluctuations, which increased the company's liabilities, that is, credit risks. For the study of its rate of return, the geometric rate of return is negative, so it accounts for a relatively large investment needed to be adjusted. Lastly, the market risk would not influence the financial situation of Tesco in a short term. However, the idiosyncratic risk should be considered because it is generated from Tesco's retail operations, and its methods of analyzing financial instrument.

\section{REFERENCES}

[1] Annual Report 2021, Reports, Results and Presentations, Investors, Tesco PLC, https://www.tescoplc.com/, Viewed 16/7/2021

[2] Diamond D. W, Rajan R. G 2001, Liquidity risk, liquidity creation, and financial fragility: A theory of banking[J]. Journal of political Economy, Vol 109(2): Pages 287-327.

[3] Eric K, Alex K \& Alan J. Marcus 2003, Geometric or Arithmetic Mean: Reconsideration, Financial Analysts Journal, Vol.59, Iss6, Pages 46-53, DOI: 10.2469/faj.v59.n6.2574

[4] Lukas B, Matt C 2013, Banks and industry groups have been joined by an unlikely ally in their protests about the accounting treatment of assets held in liquidity buffers, Liquidity, squeezed, London, Vol. 26, Iss. 5, Pages 46-47.

[5] Matthew R. Morey, Marc W. Simpson 2001, To hedge or not to hedge: the performance of simple strategies for hedging foreign exchange risk, Journal of Multinational Financial Management, Volume 11, Issue 2, Pages 213-223.

[6] Partnoy F 2002, ISDA, NASD, CFMA, and SDNY: the four horsemen of derivatives regulation. Brookings-Wharton Papers on Financial Services, 2002(1): 213-252. 